[Agr. Biol. Chem., Vol. 36, No. 13, p. 2373 2380, 1972]

\title{
Some Properties of Fructose-1,2-cyclic Phosphates and Fructose-2-phosphates
}

\author{
By Hajime Taniguchi and Michinori Nakamura \\ Department of Agricultural Chemistry, \\ The University of Tokyo, Bunkyo-ku, Tokyo
}

Received June 2, 1972

\begin{abstract}
Fructose-1,2-cyclic phosphates(F-1,2-Ps) and fructose-2-phosphates(F-2-Ps) were synthesized according to the method of Pontis and Fischer and their properties toward acid hydrolysis were examined in detail. Fructopyranose-2-phosphate(Ep-2-P) showed exactly the same properties as those reported by Pontis and Fischer. On the other hand, a part of fructofuranose-2-phosphate(Ff-2-P) was converted into the acid-stable form during acid treatment and this substance increased progressively when the sample was stored at $-20^{\circ} \mathrm{C}$ for a longer time. This acid-stable form resembled in its properties to the fructose phosphate obtained from UDP(2)-fructose by the action of nucleotide pyrophosphatase.

When treated with acid at room temperature, fructopyranose-1,2-cyclic phosphate(Fp-1,2P) was almost completely hydrolyzed into fructose and inorganic phosphate, whereas only about $50 \%$ of fructofuranose-1,2-cyclic phosphate( $\mathrm{Ff}-1,2-\mathrm{P})$ was hydrolyzed into fructose and inorganic phosphate and the remainder was hydrolyzed into fructose-1-phosphate(F-1-P). On the other hand, when treated with acid at $100^{\circ} \mathrm{C}, 90 \%$ of both cyclic phosphates were hydrolyzed into F-1-P, and fructose and inorganic phosphate were formed only slightly.
\end{abstract}

In the previous papers, ${ }^{1,2}$ we have reported that the properties of natural UDP-fructose isolated from Jerusalem artichoke tubers were not identical to those of UDP(1)-fructose and $\mathrm{UDP}(2)$-fructose synthesized from $\mathrm{F}-1-\mathrm{P}$ and F-2-P, respectively, and deduced from these results that the structure of natural UDPfructose might be UDP(2)- $\alpha$-fructofuranose whereas the structure of synthetic UDP(2)fructose was UDP(2)- $\beta$-fructofuranose.

In the course of these investigations, we observed some anomalous properties of synthetic UDP(2)-fructose and fructose phosphate obtained from it by the action of nucleotide pyrophosphatase.

In the present paper, we report some properties of $\mathrm{F}-2-\mathrm{Ps}$ and $\mathrm{F}-1,2-\mathrm{Ps}$ as synthesized by the method of Pontis and Fischer. ${ }^{3}$ Ff2-P was converted into an acid-stable form when stored at $-20^{\circ} \mathrm{C}$ and $\mathrm{F}-1,2-\mathrm{Ps}$ were hydrolyzed mainly to give F-1-P when heated in acid, whereas they were hydrolyzed mainly to give fructose and inorganic phosphate when treated in acid at room temperature.

\section{MATERIALS AND METHODS}

Materials. F-1-P was synthesized from fructose by the method of Pogell. F-1,2-PS and F-2-Ps were synthesized by the method of Pontis and Fischer ${ }^{3}$ and purified by chromatography on a column of Dowex $1 \times 4$ (borate form) according to the method of Lefebvre et al. ${ }^{5}$, All other chemicals were obtained from commercial sources.

Analytical methods. Total phosphate was determined by the modified method ${ }^{6 /}$ of Bartlett ${ }^{7)}$ or of Hurst ${ }^{8}$ after digestion with sulfuric acid. Acid-labile phosphate was determined by the modified method of Hurst after hydrolysis of the sample in $1 \mathrm{~N}$ sulfuric acid at $100^{\circ} \mathrm{C}$ for $15 \mathrm{~min}$. Usually, inorganic phosphate was determined by the method of Hurst, but in the presence of F-1,2-P and/or F-2-P, which were hydrolyzed easily into fructose and inorganic phosphate during the time necessary for color development in the Hurst's pro- 
cedure, the method of Marsh $^{91}$ was used in place of that of Hurst. In this method, the sample was treated with $1 \mathrm{~N}$ sulfuric acid so briefly that acid-labile phosphate compounds such as mentioned above were not hydrolyzed during this procedure.

Reducing sugars were determined by the method of Park and Johnson ${ }^{10}$ : with a $1 / 5$ scale. Fructose was determined by the cysteine-carbazole method of Dische and Borenfreund ${ }^{11}$ with slight modifications. ${ }^{12}$

Paper chromatography. Tôyô filter paper No. 51A was used throughout this investigation. The paper was irrigated by the descending method at $23^{\circ} \mathrm{C}$. The solvent systems used were:

A) isopropyl alcohol: ammonia: water $(7: 1: 2)^{131}$

B) methyl cellosolve: methyl ethyl ketone: $3 \mathrm{~N}$ ammonia $(7: 2: 3)^{14}$

C) ethyl alcohol: $1 \mathrm{~m}$ ammonium acetate $(\mathrm{pH} 7.5)$ $(2.5: 1)^{15 !}$

Phosphate and fructose compounds on the dried paper were detected by the molybdate spray reagent ${ }^{16}$ and the naphthoresorcinol phosphate reagent, ${ }^{17}$ respectively.

\section{RESULTS AND DISCUSSION}

\section{Fructose-2-phosphates}

Ff-2-P and Fp-2-P synthesized as described above were identical to those reported by Pontis and Fischer $^{3}$ in the following properties: 1) elution patterns from a column of Dowex 1 4(borate form), 2) relative paper chromatographic mobilities with solvent systems A) and B) (Table I), 3) response to the molybdate

TABLE I. R $\mathrm{P}_{1}$ Values of Ff-2-P and Fp-2-P iN PAPER Chromatography

On the dried paper chromatogram, phosphates were detected by molybdate spray reagent and then fructose compounds were detected by naphthoresorcinol phosphate reagent, respectively. For other details, see "Paper chromatography.'

\begin{tabular}{lccc}
\hline \multirow{3}{*}{ Compounds } & \multicolumn{3}{c}{ Solvent System } \\
\cline { 2 - 4 } & A) & B) & C) \\
\hline F-1-P & 1.78 & 2.18 & 1.33 \\
F-6-P & 1.78 & 2.40 & - \\
F-1,6-diP & 0.45 & 0.36 & - \\
Ff-2-P & 2.11 & 4.00 & 1.83 \\
Fp-2-P & 1.78 & 2.36 & 1.23 \\
\hline
\end{tabular}

spray reagent on the paper chromatogram (they gave yellow spots immediately when sprayed with the molybdate reagent).

Furthermore, Fp-2-P was completely hydrolyzed into inorganic phosphate during the Hurst's procedure and gave the hydrolysis rate constant $\left(k=0.0178 \mathrm{~min}^{-1}\right)$ at $\mathrm{pH} 4$ and at $37^{\circ} \mathrm{C}$ (Fig. 1) similar to that $(k=0.0158$ $\mathrm{min}^{-1}$ ) calculated from a similar curve given in the original paper. ${ }^{3}$,

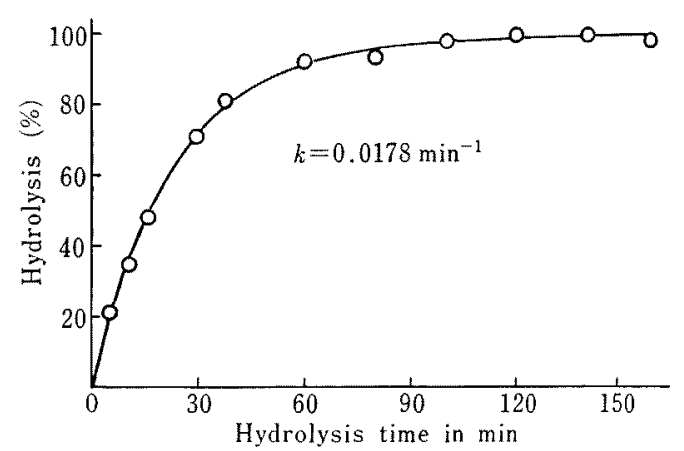

FIG. 1. Hydrolysis Curve of Fp-2-P at pH 4 and at $37^{\circ} \mathrm{C}$.

Fp-2-P $(0.7 \mu$ mole $)$ was incubated in $1.0 \mathrm{ml}$ of $0.05 \mathrm{M}$ acetate buffer $(\mathrm{pH} 4.0)$ at $37^{\circ} \mathrm{C}$ and, at intervals, $0.04 \mathrm{ml}$ aliquots were withdrawn and subjected to the determination of reducing sugar. The rate constant was calculated from this curve by the equation: $k=1 / t \log [a /(a-x)]$, in which $a$ is the initial concentration of substrate and $x$ is the concentration of product after $t$ min.

However, Ff-2-P was not hydrolyzed completely during the Hurst's procedure. As shown in Table II, only about $60 \%$ of Ff-2-P was hydrolyzed into inorganic phosphate, whereas Pontis and Fischer ${ }^{3 /}$ reported that this compound was completely hydrolyzed during the Fiske-Subbarow's procedure, in which less acid condition than that used in the Hurst's procedure is used. When this sample was hydrolyzed at $\mathrm{pH} 4$ and at $37^{\circ} \mathrm{C}$, the hydrolysis curve obtained was remarkably different from that reported by Pontis and Fischer. ${ }^{3)}$ As shown in Fig. $2 \mathrm{a}$, about $60 \%$ of Ff-2-P was hydrolyzed during the first $30 \mathrm{~min}$ and the 
Table II. Analysis of Ff-2-P and Fp-2-P.

For details, see "Analytical methods."

\begin{tabular}{ccccccc}
\hline & Molar Ratio to Total-P & & Reducing Sugar \\
\hline & Total-P & Labile-P & Inorganic-P & Fructose & $\begin{array}{c}\text { before } \\
\text { hydrolysis }\end{array}$ & $\begin{array}{c}\text { after hydrolysis } \\
\text { hydr. }\end{array}$ \\
\hline Fp-2-P & 1.00 & 1.02 & 0.98 & 1.02 & 0 & 0.97 \\
Ff-2-P & 1.00 & 1.00 & 0.56 & 1.06 & 0 & 0.97 \\
\hline
\end{tabular}

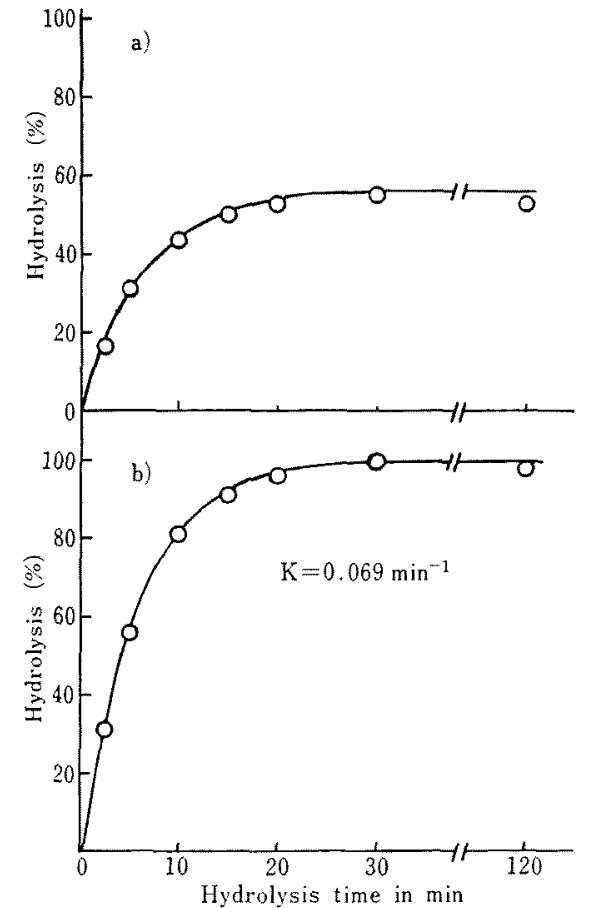

FIG. 2. Hydrolysis Curve of Ff-2-P at pH 4 and at $37^{\circ} \mathrm{C}$.

The method used was the same as in the legend Fig. 1. Fig. b) was drawn by taking the reducing value at $30 \mathrm{~min}$ of hydrolysis of Fig. a) as $100 \%$. The rate constant was calculated from the curve of Fig. b).

remaining $40 \%$ was not hydrolyzed any more during the following $90 \mathrm{~min}$. When these data were recalculated by taking the reducing power generated after $30 \mathrm{~min}$ of hydrolysis as $100 \%$, we obtained Fig. $2 b$, which was, to our surprise, very similar to that reported by
Pontis and Fischer; i.e., the hydrolysis rate constant calculated from Fig. $2 b$ was $k=$ $0.069 \mathrm{~min}^{-1}$, whereas that obtained from the data of Pontis and Fischer was $k=0.059 \mathrm{~min}^{-1}$ It may be argued that the sample used in these experiments contained some other acid-stable fructose phosphate(s) in addition to Ff-2-P. However, as the sample was shown, by paper chromatography, to be free from $F-1-P$ and other known fructose phosphates, it may rather be considered that this sample contains some unknown acid-stable substance(s).

Furthermore, the synthetic Ff-2-P was gradually converted into an acid-stable substance when stored at $-20^{\circ} \mathrm{C}$ for a longer time. Table III shows the analytical data of $\mathrm{Ff}-2-\mathrm{P}$ which was stored at $-20^{\circ} \mathrm{C}$ for 1,3 and 29 months. Each stored sample was purified by paper chromatography with solvent system A) (these samples showed practically the same mobility as that of newly synthesized Ff-2-P) and analyzed as in the case of Table I. It is clear from Table III that Ff-2-P became more acid stable when it was stored for a longer time. The sample stored for 29 months did not give a yellow spot on the paper chromatogram when sprayed with the molybdate reagent.

From these facts one may consider that the synthetic Ff-2-P contains some acid-stable substance(s) and that the content of this fraction increases gradually during its storage even at $-20^{\circ} \mathrm{C}$. Although there is no additional data pertaining to the nature of this acid- 
Table III. Analysis of Ff-2-P Stored at $-20^{\circ} \mathrm{C}$ FOR VARIOUS TIMES

For details, see "Analytical methods."

\begin{tabular}{rcccccc}
\hline \multicolumn{7}{c}{ Molar ratio to total-P } \\
\hline $\begin{array}{c}\text { Time of } \\
\text { storage } \\
\text { (month) }\end{array}$ & Total-P & Labile-P & Inorganic-P & Fructose & $\begin{array}{c}\text { Reducing Sugar } \\
\text { before } \\
\text { hydrolysis }\end{array}$ & $\begin{array}{c}\text { after } \\
\text { hydrolysis }\end{array}$ \\
\hline 1 & 1.00 & 1.00 & 0.61 & 1.05 & 0.11 & 0.97 \\
3 & 1.00 & 0.88 & 0.61 & 1.02 & 0.21 & 0.77 \\
29 & 1.00 & 0.72 & 0.00 & 0.96 & 0.04 & 0.69 \\
\hline
\end{tabular}

stable substance, in the absence of evidence against the following view, $\mathrm{Ff}-2-\mathrm{P}$ is supposed to be converted into an unknown acid-stable form or an acid-stable complex with the existing salts.

The properties of the acid-stable substance described above are quite similar to those of a fructose phosphate produced from UDP(2)fructose by the action of nucleotide pyrophosphatase reported in the previous paper. ${ }^{2)}$ The identification of this acid-stable substance is open to a further investigation.

\section{Fructose-1,2-cyclic phosphates}

Ff-1,2-P and Fp-1,2-P synthesized as described above showed the same properties as those reported in the original paper ${ }^{3)}$ in the following items; 1) elution patterns from a column of Dowex $1 \times 4$ (borate form), 2) relative paper chromatographic mobilities with solvent systems A) and B), 3) response to the molybdate spray reagent on the paper chro- matogram (they gave yellow spots when sprayed with the molybdate reagent).

The analytical data of these cyclic phosphates summarized in Table IV indicate that Ff-1, 2-P was hydrolyzed by $53 \%$ during the Hurst's procedure, whereas $\mathrm{Fp}-1,2-\mathrm{P}$ was hydrolyzed completely by the same treatment. Apparently, this seems to suggest that $F f-1,2-P$ is more stable to acid than Fp-1, 2-P.

As F-2-Ps have practically no reducing power, the fact that both cyclic phosphates have reducing power $(51 \%$ for $\mathrm{Ff}-1,2-\mathrm{P}$ and $25 \%$ for $\mathrm{Fp}-1,2-\mathrm{P}$ ) seems to be inconsistent with their structures in which the reducing OH group on $\mathrm{C}-2$ is linked to phosphate. However, in the method of Park and Johnson the sample is treated in "carbonate-cyanide solution" ( $\mathrm{pH}$ of which is about 11 ) at $100^{\circ} \mathrm{C}$ for $15 \mathrm{~min}$ so that there is possibility that a part of cyclic phosphates might be hydrolyzed to produce the reducing power in the course of this treatment. To confirm this, samples

Table IV. Analysis of Ff-1,2-P AND Fp-1,2-P

For details, see "Analytical methods."

\begin{tabular}{ccccccc}
\hline & Molar ratio to total-P & & & \multicolumn{2}{c}{ Reducing sugar } \\
\hline & Total-P & Labile-P & Inorganic-P & Fructose & $\begin{array}{c}\text { before } \begin{array}{c}\text { befter } \\
\text { hydrolysis }\end{array} \\
\text { hydrolysis }\end{array}$ \\
\hline Ff-1,2-P & 1.00 & 0.98 & 0.53 & 1.00 & 0.51 & 0.73 \\
Fp-1,2-P & 1.00 & 1.12 & 1.01 & 1.09 & 0.25 & 0.69 \\
\hline
\end{tabular}


Table V. Alkali Treatment of Ff-1,2-P AND Fp-1,2-P

To $0.5 \mathrm{ml}$ of samples containing $0.7 \sim 1.0 \mu$ mole of cyclic phosphates was added $0.5 \mathrm{ml}$ of "carbonatecyanide solution" and the reaction mixtures were heated in a boiling water bath for $15 \mathrm{~min}$. From each reaction mixtures, $0.05 \mathrm{ml}$ aliquots were withdrawn and subjected to phosphate determination by the method of Marsh with a $1 / 5$ scale and by the modified method of Hurst with a $1 / 5$ scale. Samples not treated with alkali were subjected to the same determination.

\begin{tabular}{llcc}
\hline & \multicolumn{2}{c}{ Molar ratio to total-P } \\
\cline { 3 - 4 } & by Marsh & by Hurst \\
\hline Ff-1,2-P & no treatment & 0.06 & 0.59 \\
& treated with alkali & 0.55 & 0.67 \\
\hline Fp-1,2-P & no treatment & 0.06 & 0.97 \\
& treated with alkali & 0.46 & 0.73 \\
\hline
\end{tabular}

were heated in "carbonate-cyanide solution" at $100^{\circ} \mathrm{C}$ for $15 \mathrm{~min}$ and then subjected to phosphate determination by the methods of Hurst and of Marsh. Although the results somewhat varied in repeated experiments, the figures shown in Table $\mathrm{V}$ indicate that $55 \%$ of $\mathrm{Ff}-1,2-\mathrm{P}$ and $46 \%$ of $\mathrm{Fp}-1,2-\mathrm{P}$ were hydrolyzed into the so-called "true inorganic phosphate." Since in alkaline hydrolysis fructose compounds may be decomposed into various fragments, the "true inorganic phosphate" fractions may contain some extremely acid-labile phosphate compounds. However, these results clearly show that, contrary to F-2-Ps, F-1,2-Ps are at least partially decomposed during the procedure of Park and Johnson. No new fructose phosphate compound was produced as examined by paper chromatography after treatment of cyclic phosphates with "carbonate-cyanide solution."

As shown in Table IV, the reducing value of cyclic phosphates after acid hydrolysis in $0.01 \mathrm{~N}$ hydrochloric acid at $100^{\circ} \mathrm{C}$ for $15 \mathrm{~min}$ indicates that, contrary to our expectation, they were not hydrolyzed completely into fructose and inorganic phosphate during this procedure. Table VI shows the molar ratios of inorganic phosphate and reducing sugar before and after hydrolysis of cyclic phosphates in $0.01 \mathrm{~N}$ hydrochloric acid at $100^{\circ} \mathrm{C}$ for 5 min (there was no difference in the results

Table VI. ACID Hydrolysis of Ff-1,2-P AND Fp-1,2-P

To $0.9 \mathrm{ml}$ of samples containing $1.3 \sim 1.5 \mu$ moles of cyclic phosphates was added $0.1 \mathrm{ml}$ of $0.1 \mathrm{~N}$ hydrochloric acid and the reaction mixtures were heated in a boiling water bath for 0 or $5 \mathrm{~min}$, respectively. From this reaction mixutres, $0.1 \mathrm{ml}$ aliquots were withdrawn and neutralized immediately with $0.1 \mathrm{~N}$ sodium hydroxide and then subjected to the determination of reducing sugar by the method of Park and Johnson with a $1 / 5$ scale. Another $0.2 \mathrm{ml}$ aliquots were withdrawn from the same reaction mixtures and subjected directly to phosphate determination by the modified method of Hurst.

\begin{tabular}{lrcc}
\hline & $\begin{array}{c}\text { Hydrolysis in } \\
0.01 \mathrm{~N} \mathrm{HCl}\end{array}$ & $\begin{array}{c}\text { Molar ratio to total-P } \\
\text { Inorganic- }\end{array}$ & $\begin{array}{c}\text { Reducing } \\
\text { sugar }\end{array}$ \\
\hline Ff-1,2-P & $0^{\circ} \mathrm{C}$ for $0 \mathrm{~min}$ & 0.55 & 0.51 \\
& $100^{\circ} \mathrm{C}$ for $5 \mathrm{~min}$ & 0.09 & 0.76 \\
Fp-1,2-P & $0^{\circ} \mathrm{C}$ for $0 \mathrm{~min}$ & 0.94 & 0.29 \\
& $100^{\circ} \mathrm{C}$ for $5 \mathrm{~min}$ & 0.11 & 0.69 \\
\hline
\end{tabular}

whether the samples were hydrolyzed for $5 \mathrm{~min}$ or $15 \mathrm{~min}$ ). This table shows that both cyclic phosphates were hydrolyzed only by about $10 \%$ into inorganic phosphate and that the remaining portion has been changed into an acid-stable compound. Taking into account of the fact that F-1-P was about $60 \%$ of reducing power as compared to free fructose, "1 this acid-stable compound is supposed to be $\mathrm{F}-1-\mathrm{P}$ from the values of reducing sugar after acid hydrolysis.

Table VII shows the paper chromatographic identification of hydrolysis products of cyclic phosphates when they were treated in $0.01 \mathrm{~N}$ hydrochloric acid at $100^{\circ} \mathrm{C}$ for $5 \mathrm{~min}$ and in $1 \mathrm{~N}$ sulfuric acid at room temperature for 30 min (the condition used in the Hurst's procedure). The facts that (i) inorganic 
Table VII. Paper Chromatographic Identification of Acid Hydrolysis Products of Ff-1,2-P and Fp-1,2-P

The papers were developed with solvent system A). For other details, see the text.

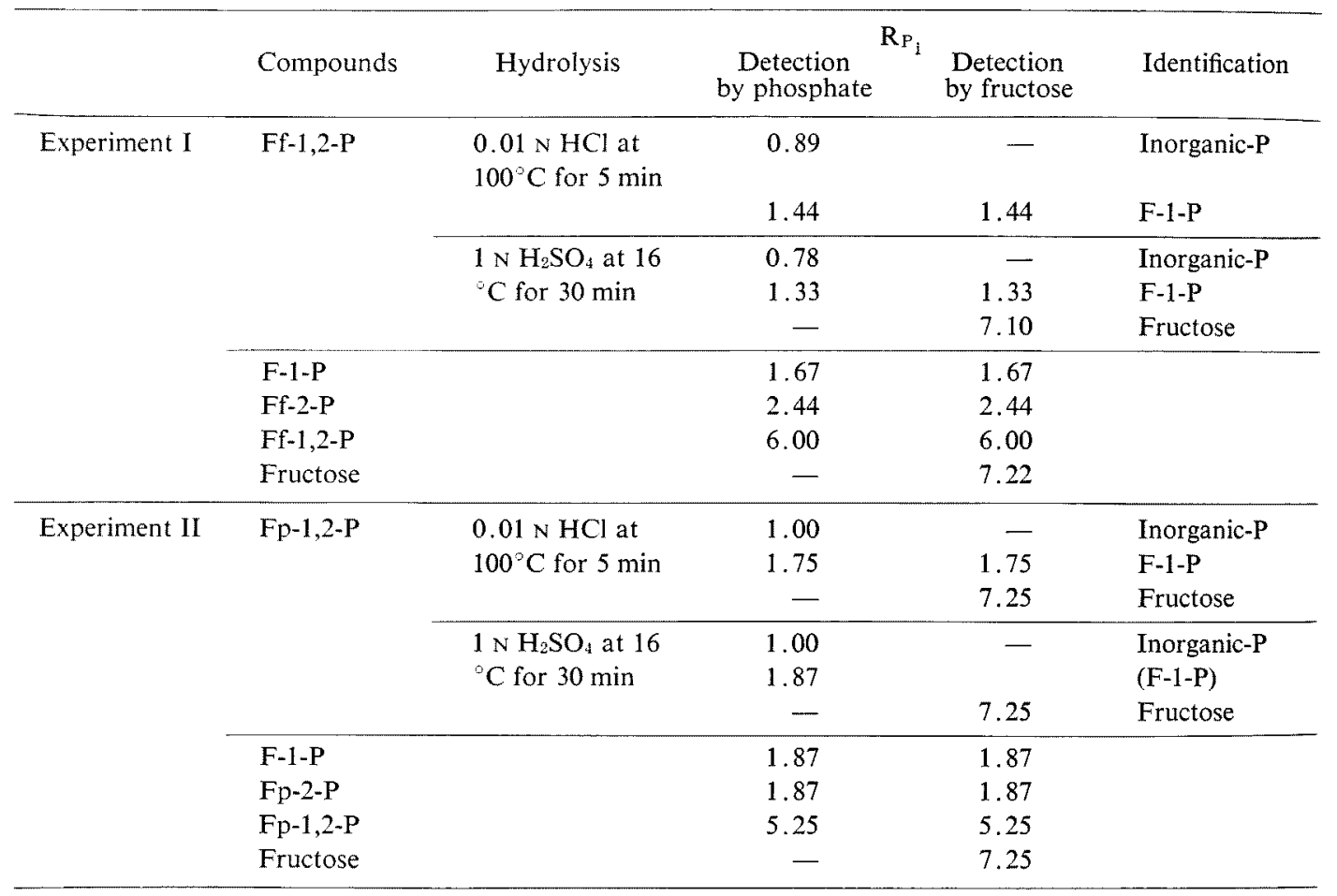

Table VIII. Behayior of Ff-1,2-P and Fp-1,2-P Against ACID TREatments

Cyclic phosphates $(0.12 \sim 0.13 \mu$ mole) in a final volume of $1.0 \mathrm{ml}$ were preincubated as indicated in the table, then they were subjected immediately to phosphate determination by the modified method of Hurst. Samples dissolved in distilled water showed the $\mathrm{pH}$ of $6 \sim 7$ and were subjected to the same run.

\begin{tabular}{|c|c|c|c|c|}
\hline \multicolumn{3}{|c|}{ Preincubation } & \multicolumn{2}{|c|}{ Molar ratio to total-P } \\
\hline $\begin{array}{l}\text { Acid } \\
\text { strength }\end{array}$ & $\begin{array}{c}\text { Temperature } \\
\left({ }^{\circ} \mathrm{C}\right)\end{array}$ & $\begin{array}{l}\text { Time } \\
(\min )\end{array}$ & Ff-1,2-P & Fp-1,2-P \\
\hline pH $6 \sim 7$ & $\begin{array}{r}24 \\
100\end{array}$ & $\begin{array}{l}15 \\
15\end{array}$ & $\begin{array}{l}0.50 \\
0.24\end{array}$ & $\begin{array}{l}0.98 \\
0.89\end{array}$ \\
\hline $0.01 \mathrm{~N} \mathrm{H}_{2} \mathrm{SO}_{4}$ & $\begin{array}{r}24 \\
100\end{array}$ & $\begin{array}{l}15 \\
15\end{array}$ & $\begin{array}{l}0.38 \\
0.07\end{array}$ & $\begin{array}{l}0.97 \\
0.10\end{array}$ \\
\hline $0.01 \mathrm{~N} \mathrm{HCl}$ & $\begin{array}{r}24 \\
100\end{array}$ & $\begin{array}{l}15 \\
15\end{array}$ & $\begin{array}{l}0.38 \\
0.09\end{array}$ & $\begin{array}{l}0.89 \\
0.11\end{array}$ \\
\hline \multicolumn{3}{|c|}{ without preincubation } & 0.49 & 0.93 \\
\hline
\end{tabular}


phosphate was detected, while no fructose was detected after treatment of $\mathrm{Ff}-1,2-\mathrm{P}$ in $0.01 \mathrm{~N}$ hydrochloric acid at $100^{\circ} \mathrm{C}$ for $5 \mathrm{~min}$ and that (ii) fructose could not be detected while inorganic phosphate was located at the position of $\mathrm{F}-1-\mathrm{P}$ after treatment of $\mathrm{Fp}-\mathrm{l}$, $2-\mathrm{P}$ in $1 \mathrm{~N}$ sulfuric acid at $16^{\circ} \mathrm{C}$ for $30 \mathrm{~min}$, were considered to be due to the relatively low sensitivity of fructose to the spray reagent used. Accordingly, Table VII shows that both cyclic phosphates were hydrolyzed into F-1-P, fructose and inorganic phosphate by either acid treatment.

In view of the results described above, it is considered that in the hydrolysis conditions used in Table VII, the cyclic phosphates were first hydrolyzed into F-1-P and F-2-Ps in various ratios and the latter were in turn hydrolyzed into fructose and inorganic phosphate as soon as they were formed. The ratios of $\mathrm{F}-1-\mathrm{P}$ and $\mathrm{F}-2-\mathrm{Ps}$ produced at first were calculated from the data of Tables IV and VI and the hydrolytic pathways of cyclic phosphates in acid were deduced as shown in Fig. 3. It is clear from this figure that with treatment in $1 \mathrm{~N}$ sulfuric acid at room tem- perature for $15 \mathrm{~min}, 53 \sim 55 \%$ of $\mathrm{Ff}-1,2-\mathrm{P}$ was hydrolyzed into $\mathrm{Ff}-2-\mathrm{P}$ which was then rapidly hydrolyzed into fructose and inorganic phosphate and the remainder was hydrolyzed into $\mathrm{F}-1-\mathrm{P}$. On the other hand, Fp-1,2-P was hydrolyzed almost exclusively into $\mathrm{Fp}-2-\mathrm{P}$ which was also rapidly hydrolyzed into fructose and inorganic phosphate. Now, when cyclic phosphates were hydrolyzed in $0.01 \mathrm{~N}$ hydrochloric acid at $100^{\circ} \mathrm{C}$ for $5 \mathrm{~min}$, about $90 \%$ of each cyclic phosphate was hydrolyzed into F-1-P and the remaining $10 \%$ was hydrolyzed into Ff-1-P or Fp-2-P which were further hydrolyzed into fructose and inorganic phosphate.

To decide whether the difference in the hydrolytic pathways of cyclic phosphates in the above two acid treatments is due to the concentration of acid used or to the property of anions used or to the temperature during acid treatments, the cyclic phosphates were treated under various conditions. Inorganic phosphate produced was determined by the modified method of Hurst and compared with total phosphate determined by the modified method of Bartlett. The results obtained are shown
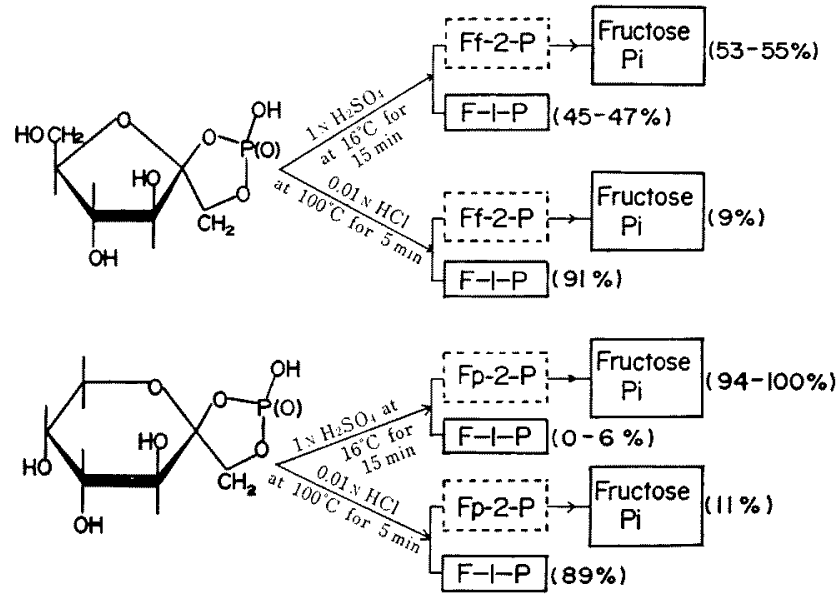

Fig. 3. Hydrolytic Pathways of Ff-1,2-P and Fp-1,2-P in Acid.

Figures in parenthesis were calculated from the data of Tables IV and VI. Fructose and inorganic phosphate $\left(P_{i}\right)$ are considered to be produced through the substances enclosed by the dotted line. 
in Table VIII, which indicates that neither the property of anions nor the concentration of acids cause the difference mentioned above. It is clear that the temperature during the acid hydrolysis is responsible for the difference mentioned above. Especially in the case of Ff-1,2-P, the temperature caused the difference even at neutral $\mathrm{pH}$.

As in the case of glucose-1,2-cyclic phosphate, ${ }^{15}$ it is generally accepted that when cyclic sugar phosphate is hydrolyzed in acid, between the two sugar phosphates to be produced, the one which is more acid stable than the other is produced more in amount. However, in the acid hydrolysis of F-1,2-Ps at room temperature, the amont of F-2-Ps formed was more than that of $\mathrm{F}-1-\mathrm{P}$ formed, whereas in acid hydrolysis at $100^{\circ} \mathrm{C}$, the amount of $\mathrm{F}-1-\mathrm{P}$ formed was much more than that of F-2-Ps formed in agreement with the case of glucose-1,2-cyclic phosphate.

The precise mechanism of the hydrolytic pathways of $\mathrm{F}-1,2-\mathrm{Ps}$ in acid is not known as yet, and offers an inviting theme for further investigations.

\section{REFERENCES}

1) H. Taniguchi and M. Nakamura, Agr. Biol.
Chem., 32, 580 (1968).

2) H. Taniguchi and M. Nakamura, ibid, 36, 2185 (1972).

3) H. G. Pontis and C. L. Fischer., Biochem. J., 89, 452 (1963).

4) B. M. Pogell, "Biochemical Preparations," Vol. VII, ed. by H. A. Lardy, John Wiley and Sons Inc., New York, N.Y., 1960, p. 58.

5) M. J. Lefebvre, N. S. Gonzalez and H. G. Pontis, J. Chromatog., 15, 495 (1964).

6) M. Nakamura, Kagaku to Seibutsu, 3, 39 (1965).

7) G. R. Bartlett, J. Biol. Chem., 234, 459 (1959).

8) R. O. Hurst, Can. I. Biochem., 42, 287 (1964).

9) B. B. Marsh, Biochim. Biophys. Acta, 32, 257 (1959).

10) J. T. Park and M. J. Johnson, J. Biol. Chem., 181, 149 (1949).

11) Z. Dische and E. Borenfreund, ibid., 192, 583 (1951).

12) M. Nakamura, Agr. Biol. Chem, 32, 701 (1968).

13) D. M. Brown and A. R. Todd, J. Chem. Soc., 1953, 2040.

14) D. C. Mortimer, Can. J. Chem., 30, 653 (1952).

15) A. C. Paladini and L. F. Leloir, Biochem. J., 51, 426 (1952).

16) R. S. Bandurski and B. Axelrod, J. Biol. Chem., 193, 405 (1951).

17) V. Prey, H. Berbalk and M. Kausz, Mikrochim. Acta, 1961, 968. 